\title{
Protein Phosphatase-Dependent Circadian Regulation of Intermediate-Term Associative Memory
}

\author{
Maximilian Michel, Jacob S. Gardner, Charity L. Green, Chelsea L. Organ, and Lisa C. Lyons \\ Department of Biological Science, Program in Neuroscience, Florida State University, Tallahassee, Florida 32306-4295
}

The endogenous circadian clock is a principal factor modulating memory across species. Determining the processes through which the circadian clock modulates memory formation is a key issue in understanding and identifying mechanisms to improve memory. We used the marine mollusk Aplysia californica to investigate circadian modulation of intermediate-term memory (ITM) and the mechanisms through which the circadian clock phase specifically suppresses memory using the operant learning paradigm, learning that food is inedible. We found that ITM, a temporally and mechanistically distinct form of memory, is rhythmically expressed under light-dark and constant conditions when induced by either massed or spaced training. Strong circadian regulation of ITM occurs with memory exhibited only by animals trained during the early subjective day; no apparent memory is expressed when training occurs during the late subjective day or night. Given the necessity of multiple persistent kinase cascades for ITM, we investigated whether protein phosphatase activity affected circadian modulation. Inhibition of protein phosphatases 1 and 2A blocked ITM when animals were trained during the early (subjective) day while resulting in phase-specific memory rescue when animals were trained late in the subjective day and early night. In contrast, inhibition of calcineurin did not block ITM when animals were trained during the early day and permitted ITM when animals were trained during the late subjective day, early evening, and throughout the night. These results demonstrate that levels of protein phosphatase activity are critical regulators of ITM and one mechanism through which the circadian clock regulates memory formation.

\section{Introduction}

The formation and maintenance of memory are dynamic molecular processes modulated by multiple factors, including health, age, and time of day. The circadian clock modulates learning and memory across species and learning paradigms (Chaudhury and Colwell, 2002; Fernandez et al., 2003; Valentinuzzi et al., 2004; Decker et al., 2007; Rawashdeh et al., 2007; Barbosa and Albuquerque, 2008; Ruby et al., 2008; Valentinuzzi et al., 2008; Lyons and Roman, 2009; Gritton et al., 2012; Wright et al., 2012). Time of training appears to be a central modulator of long-term memory (LTM), suggesting that circadian regulation of memory occurs during the induction or molecular consolidation phases (Folkard and Monk, 1980; Fernandez et al., 2003; Lyons et al., 2005; Decker et al., 2007; Barbosa and Albuquerque, 2008). Although the behavioral evidence for circadian modulation of memory has greatly increased over the past decade, relatively few studies have investigated the mechanisms through which memory is modulated, with almost no information available on intermediate-term memory (ITM). Defining and understanding the mechanisms through which endogenous factors target mem-

Received Sept. 24, 2012; revised Jan. 24, 2013; accepted Jan. 30, 2013.

Author contributions: M.M. and L.C.L. designed research; M.M., J.S.G., C.L.G., C.L.O., and L.C.L. performed research; M.M. and L.C.L. analyzed data; M.M. and L.C.L. wrote the paper.

This work was supported by National Institute of Mental Health Grant R01MH81012 to L.C.L.

The authors declare no competing financial interests.

Correspondence should be addressed to Dr. Lisa C. Lyons, Department of Biological Science, Florida State University, 319 Stadium Drive, Tallahassee, FL 32306-4295. E-mail: lyons@bio.fsu.edu.

M. Michel's present address is Department of Molecular Physiology and Biophysics, Vanderbilt University School of Medicine, Nashville, TN 37232.

DOI:10.1523/JNEUROSCI.4534-12.2013

Copyright $\odot 2013$ the authors $\quad 0270-6474 / 13 / 334605-09 \$ 15.00 / 0$ ory formation, maintenance and recall are crucial to identifying the means of improving memory and performance.

The marine mollusk Aplysia californica has proven an excellent model for elucidating in vivo interactions between the circadian clock and memory. In this system, the circadian clock modulates nonassociative intermediate- and long-term sensitization (Fernandez et al., 2003; Lyons et al., 2008) and long-term associative memory (Lyons et al., 2005). We used an associative operant learning paradigm, learning that food is inedible (LFI), to characterize circadian modulation of ITM and identify molecular mechanisms through which circadian regulation occurs. For LFI memory, a single massed training session induces temporally and mechanistically distinct memory forms, including shortterm memory (STM; $30 \mathrm{~min})$, ITM (4-6 h), and LTM (24 h) (Michel et al., 2012).

In this study, we characterized circadian modulation of ITM and examined underlying mechanisms. We found that the circadian clock regulates the induction of LFI memory by both massed and spaced training. Surprisingly, the permissive period for induction of ITM is strictly limited to a few hours in the early (subjective) day, in contrast to LTM for which training at any time during the day results in robust memory. Restricted neurotransmitter availability or the drive to feed do not appear to underlie the circadian regulation of ITM as exogenously supplying the neurotransmitter nitric oxide (NO) is insufficient to rescue ITM. We found that levels of protein phophatase activity are a key factor in ITM formation. Inhibitors of protein phosphatase 1 (PP1) and protein phosphatase 2A (PP2A) injected before training blocked memory when animals were trained during the early subjective day and rescued memory when animals were 
trained during the late subjective day and early night. However, restoration of ITM was only effective when inhibitors were applied before training. During the late subjective day and throughout the night inhibition of calcineurin (protein phosphatase 3, formerly PP2B) before training rescued intermediate-term LFI memory. These results present insights into the mechanisms through which the circadian clock modulates memory formation.

\section{Materials and Methods}

\section{Animal maintenance}

Hermaphroditic A. californica (Alacrity; Charles Hollahan, Santa Barbara, CA) weighing $\sim 100-200 \mathrm{~g}$ were housed in individual boxes in 110 gallon tanks of artificial seawater (ASW; Instant Ocean Aquarium Systems) at $15^{\circ} \mathrm{C}$ maintained in $12 \mathrm{~h} \mathrm{light} / 12 \mathrm{~h}$ dark cycles. Animals were fed to satiation with laver seaweed 5-6 d before all experiments. Dim red light was used for experiments conducted in darkness. All experiments were performed at $15^{\circ} \mathrm{C}$. Zeitgeber time (ZT) 0 refers to dawn or "lights on" while ZT 12 represents dusk and the time lights were turned off. For experiments conducted in constant darkness (DD), the Circadian time (CT) refers to the subjective free-running time of the animal with respect to the previous $12 \mathrm{~h}$ light $/ 12 \mathrm{~h}$ dark cycle entrainment cycle. In Aplysia, the free-running circadian rhythms under DD are $\sim 24 \mathrm{~h}$ (Lickey et al., 1976; Takahashi et al., 2001) so that the CT reflects the previous ZT.

\section{Behavioral training and testing}

Before LFI training, animals were removed from appetitive stimuli for 5-6 d.

Massed training. LFI training was performed as described previously (Susswein et al., 1986; Botzer et al., 1998; Katzoff et al., 2002; Lyons et al., 2005) modified using a 25 min abbreviated training protocol (Michel et al., 2012). Massed LFI training consisted of a single training session in which animals were presented with a small piece of laver seaweed wrapped in netting that could not be swallowed. Animals responded by head waving, biting, and attempts to swallow the netted seaweed. Four hours after the end of training, we tested for ITM by presenting the netted seaweed to the animal and allowing the animal to respond with biting and swallowing attempts until the animal stopped responding for $3 \mathrm{~min}$ without attempts to ingest the seaweed. Memory was expressed as a reduction in the total response time compared with the length of the training session or compared with response times of naive animals. Naive animals were handled similarly to trained animals.

Spaced training. Spaced training used three $10 \mathrm{~min}$ sessions with an interstimulus interval (ISI) of $15 \mathrm{~min}$. Memory was expressed as a decrease in response time compared with the cumulative training time. All circadian experiments were performed on the second day of DD.

\section{Drug treatments}

For experiments investigating NO signaling, L-NAME was injected 30 min before training at a concentration of $1 \mathrm{ml}$ of $10 \mathrm{mg} / \mathrm{ml} \mathrm{L-NAME}$ (Sigma) per $100 \mathrm{~g}$ body mass. Exogenous NO was supplied using SNAP delivered via injection of $1 \mathrm{ml}$ of $1 \mathrm{mg} / \mathrm{ml}$ stock solution per $100 \mathrm{~g}$ body mass $10 \mathrm{~min}$ before training. Vehicle injections consisted of $1 \mathrm{ml}$ filter sterilized Instant Ocean (ASW) per 100 g body mass. For experiments investigating the role of protein phosphatases, animals were injected in the anterior half of the foot with either vehicle (ASW or DMSO), okadaic acid (Biomol; injection of $1 \mathrm{ml} / 100 \mathrm{~g} 6.5 \mu \mathrm{M}$ for $\sim 100 \mathrm{nM}$ systemic concentration) or calyculin A (Biomol; injection of $1 \mathrm{ml} / 100 \mathrm{~g} 0.65 \mu \mathrm{M}$ solution for $\sim 10 \mathrm{~nm}$ in the animal) $30 \mathrm{~min}$ before training. FK 506 (Sigma) was made up to $5 \mathrm{~mm}$ in DMSO and injected as $130 \mu \mathrm{l} / 100 \mathrm{~g}$ to obtain an approximate systemic concentration of $10 \mu \mathrm{M}$.

\section{Statistics}

Statistical analysis of the data was by ANOVA with Bonferroni post hoc analyses. $p<0.05$ was considered significant.

\section{Results}

\section{ITM induced by massed training is severely phase-restricted under LD cycles}

During memory formation for LFI, animals associate a specific seaweed wrapped in net with the failure of swallowing attempts, resulting in decreased response times upon representation of the netted seaweed (Susswein et al., 1986; Michel et al., 2011a). Recently, we reported the existence of ITM induced by the same massed training protocol that produces STM and LTM (Michel et al., 2012). Massed training of animals during the early day at ZT 3 induces robust ITM expressed $4-6 \mathrm{~h}$ after training that completely disappears by $9 \mathrm{~h}$ after training (Michel et al., 2012). However, these findings contrast with earlier research demonstrating that only a spaced training protocol successfully induced intermediate-term LFI memory (Botzer et al., 1998). Potentially circadian or diurnal regulation of memory accounted for the ineffectiveness of massed training-induced ITM in these earlier studies as the circadian clock strongly modulates memory for intermediate- and long-term sensitization (Fernandez et al., 2003; Lyons et al., 2008) and long-term LFI in Aplysia (Lyons et al., 2005). To investigate possible diurnal regulation of massed training-induced ITM, we trained animals at 6 time points throughout the LD cycle and tested the animals $4 \mathrm{~h}$ later. To ensure uniform testing of the animals relative to the start of training, all animals were trained using a 25 min massed training protocol previously shown sufficient to induce ITM (Michel et al., 2012). As the $25 \mathrm{~min}$ training time is below the mean training time observed in previous studies when the animals were trained using a full-length protocol (Michel et al., 2011a, 2011b, 2012), the netted seaweed had to be gently extracted from the animal's mouth without exertion of force, resulting in some variation in training times (mean training time for animals trained using 25 min protocol shown in Fig. 1:25.58 $\pm 0.26 \mathrm{~min}, n=134$ ). Memory was assessed as a decrease in response times relative to training times or naive animals. We found that significant diurnal variation occurred in massed training-induced ITM with the induction of ITM phase-limited to the early day (Fig. 1A; ANOVA: $\left.F_{(12,78)}=4.63, p<0.0001\right)$. Only animals trained at ZT $3(3 \mathrm{~h}$ after lights on) exhibited intermediate-term LFI memory upon testing.

\section{Circadian clock strongly regulates massed training- induced ITM}

Potentially, the limited effectiveness of massed training-induced ITM resulted from a light-induced facilitation of the massed training protocol (i.e., an upregulation of metabolism, gene expression, or protein synthesis associated with dawn that persists for only a few hours). For example, the immediate early gene $A p C / E B P$ associated with LTM in Aplysia (Alberini et al., 1994; Levitan et al., 2008) is acutely induced by light (Hattar et al., 2002). Although ITM is not dependent upon transcription, a similar type of acute light effect on molecular processes could result in a narrow window for induction of ITM when animals are trained using massed training. Alternatively, the diurnal regulation of massed ITM could be the result of regulation of ITM by the circadian clock. To differentiate between an acute light effect and circadian regulation of ITM, animals were trained and tested at 6 time points on the second day of DD. As in $12 \mathrm{~h}$ light/ $12 \mathrm{~h}$ dark cycles, animals trained and tested at CT 3 exhibited robust ITM, whereas animals trained at any other time point did not show significant memory (Fig. $1 B$; ANOVA: $F_{(12,118)}=9.75, p<0.0001$ ).

To define the permissible time frame for the induction of ITM, we trained animals at hourly time points between CT 1 and 

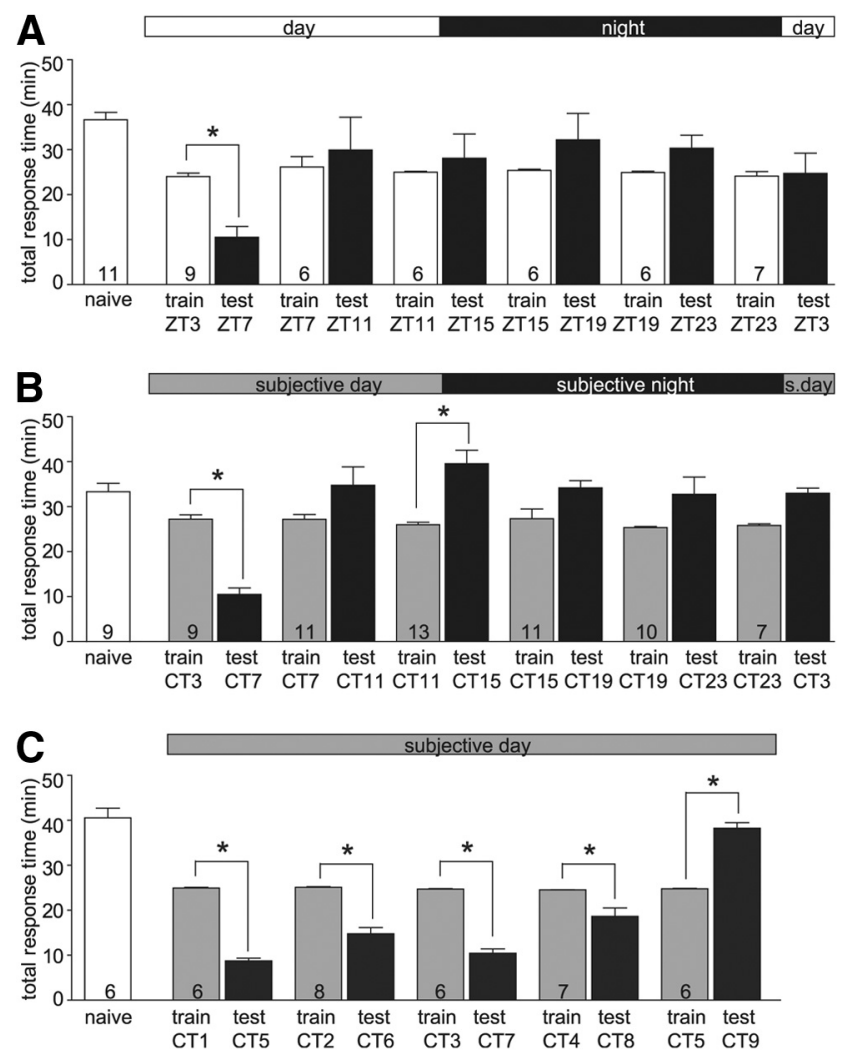

Figure 1. Diurnal and circadian regulation of massed training-induced ITM. Animals were trained using a $25 \mathrm{~min}$ training protocol at six time points and tested for LFI memory $4 \mathrm{~h}$ after training. Mean response times and standard errors are plotted. $\boldsymbol{A}, 0$ nly animals trained early in the morning at ZT 3 demonstrated significantly decreased response times during testing. * Significant memory ( $p<0.05$, post hoc analyses using Bonferroni's multiple-comparison test). Number of animals $(N)$ for each group is shown in the figure. $\boldsymbol{B}$, Animals were trained at six time points on the second day of constant darkness and tested $4 \mathrm{~h}$ later. Robust ITM was exhibited only when animals were trained at CT 3.C, To determine the temporal window for induction of ITM, animals were trained at hourly time points between CT 1 and CT 5. Significant ITM was observed when animals were trained between $\mathrm{C} T 1$ and $\mathrm{CT} 4$, with no decrease in response times observed when animals were trained at CT 5.

CT 5. As predicted, training for ITM was effective during a narrow window, with animals trained at CT 1, CT 2, CT 3, and CT 4 demonstrating significantly decreased response times upon testing (Fig. $1 C$; ANOVA: $F_{(10,61)}=78.61, p<0.0001$ ). However, animals trained at CT 5 failed to demonstrate ITM, displaying response times similar to naive animals (Fig. $1 C$ ). These results explicitly demonstrate that massed training-induced ITM is strongly regulated by the circadian clock.

\section{Diurnal and circadian regulation of ITM induced by spaced training}

If the massed training protocol used to induce ITM resulted in weaker memory, this could potentially account for the observed phase restriction for induction. As seen with many learning paradigms, spaced training protocols often result in more robust, longer-lasting memories compared with massed training (Carew et al., 1972; Beck et al., 2000; Menzel et al., 2001; Sutton et al., 2002; Philips et al., 2007). Additionally, stronger training protocols may occlude circadian modulation of memory as previously shown in mice (Chaudhury and Colwell, 2002). To test this possibility, we used a spaced training protocol adapted from Botzer et al. (1998), in which animals were trained using three $10 \mathrm{~min}$ sessions with a 15 min ISI (Fig. 2A). Fifteen minute ISIs in spaced
A
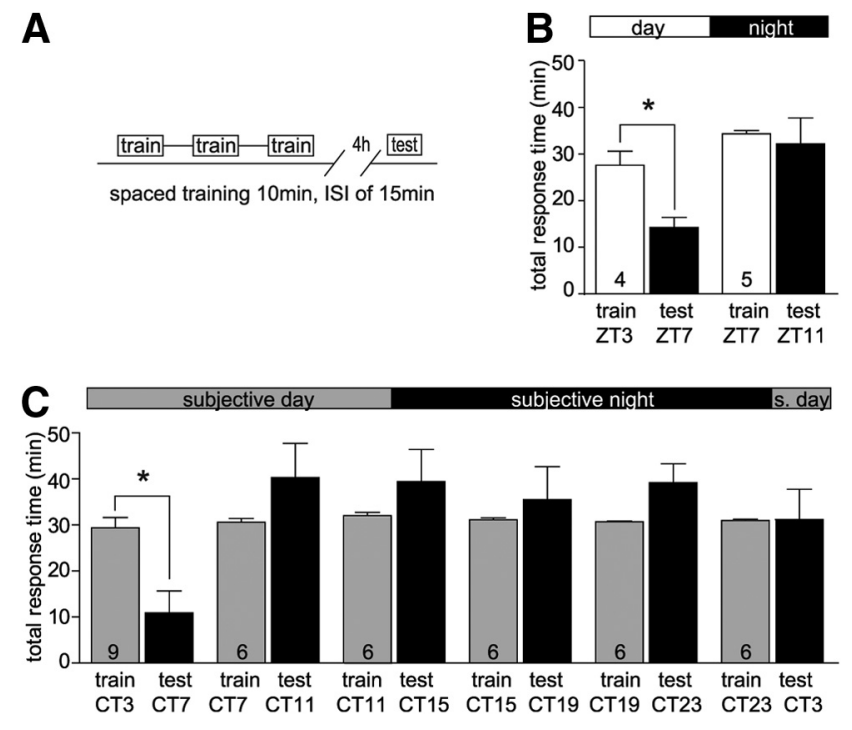

Figure 2. The circadian clock regulates spaced training-induced ITM. $\boldsymbol{A}$, Schematic diagram of the spaced training protocol is shown and consists of three 10 min training sessions with a 15 min ISI. Testing occurred $4 \mathrm{~h}$ after training. $\boldsymbol{B}$, As with massed training, animals trained at ZT 3 but not ZT 7 exhibited significantly decreased response times during testing, denoting robust ITM. C, Animals were trained at six time points on the second day of DD and were tested $4 \mathrm{~h}$ later. As previously, only animals trained at CT 3 exhibited robust ITM. The $n$ values for all groups are shown in the figure. ${ }^{*} p<0.05$ (post hoc analyses using Bonferroni's multiple-comparison test).

training protocols results in robust memory in Aplysia and Drosophila (Beck et al., 2000; Sutton et al., 2002). We hypothesized that the spaced training protocol conducted at any time during the day would be effective in inducing ITM with circadian restrictions on ITM observed only during the night, similar to the rhythm previously reported for intermediate-term sensitization of the tail-siphon withdrawal reflex in Aplysia (Lyons et al., 2008). Surprisingly, we found that, similar to massed training-induced ITM, animals failed to demonstrate ITM when trained with spaced trials at ZT 7, although animals showed robust memory when trained at ZT 3 (Fig. $2 B$; ANOVA: $F_{(3,14)}=6.17, p<0.01$ ). We investigated whether the circadian clock regulated ITM after spaced training in the same manner as massed training-induced ITM by training and testing the animals at six time points on the second day of DD. We found that the rhythm in spaced ITM resembled the circadian rhythm observed for ITM-induced by massed training with significant memory observed only when animals were trained at CT 3 (Fig. 2C; ANOVA: $F_{(11,66)}=3.27$, $p<0.01)$. Thus, the circadian clock appears to strongly regulate ITM with inhibition of memory during the late subjective day and during the night. These results reflect a considerably more restrictive circadian regulation of memory than what has been observed previously in Aplysia or other model systems.

\section{Application of exogenous NO does not rescue ITM}

The sharply defined circadian rhythm of ITM with its narrow induction window is reminiscent of the circadian rhythms observed for some sensory systems, such as olfactory sensitivity in Drosophila (Krishnan et al., 1999). LFI memory likely involves olfactory and gustatory sensory responses in associating specific seaweeds with the failed swallowing attempts. However, no time of day differences exist in the latencies for animals to display appetitive behaviors to the netted seaweed (Lyons et al., 2005; data not shown) and STM is not regulated by the circadian clock (Lyons et al., 2005), suggesting that differences in sensory re- 
sponses do not underlie the circadian modulation. Potentially, a strong circadian rhythm in feeding behavior could limit the expression of memory that a specific food is inedible. A. californica exhibit diurnal rhythms in feeding behavior with increased appetitive and consummatory behaviors observed during the day (Kupfermann, 1974; Levenson et al., 1999). In Aplysia, NO acts as an inhibitory modulator of feeding responses (Miller et al., 2011) and as a necessary neurotransmitter for LFI memory formation (Katzoff et al., 2002, 2006), making NO an excellent potential candidate for circadian regulation of ITM. If the phase restriction of ITM was the result of increased drive for feeding during the late afternoon time points or circadian regulation of NO neurotransmission, we would predict that application of exogenous NO should rescue memory expression. Treatment with an NO donor has previously been shown to facilitate lip stimulation, a subthreshold training paradigm for LFI (Katzoff et al., 2006).

To verify that NO was required for massed training-induced LFI, we injected the animals with an inhibitor of NO synthase, L-NAME, 30 min before training of animals at ZT 3. As predicted, animals injected with L-NAME demonstrated no ITM, whereas vehicle-injected animals exhibited significantly decreased response times (Fig. 3A; ANOVA: $F_{(3,28)}=11.62, p<0.001$ ). To determine whether facilitating NO signaling rescued ITM, animals were injected with the exogenous NO source SNAP (1 ml/ $100 \mathrm{~g}$ body weight of $1 \mathrm{mg} / \mathrm{ml}$ stock in ASW) $10 \mathrm{~min}$ before LFI training at either CT 7 during the subjective day or at CT 15 during the subjective night. Treated animals and vehicle-injected animals were tested $4 \mathrm{~h}$ after training. Treatment with SNAP did not rescue ITM expression when animals were trained at CT 7 or CT 15, as treated animals exhibited response times similar to vehicle-injected and naive animals (Fig. $3 B$; ANOVA: $F_{(5,54)}=$ $0.40, p=0.84$ ). Thus, supplementing NO signaling with exogenous NO before training appears to have no bearing on circadian regulation of ITM during either the subjective day or the subjective night.

Inhibiting protein phosphatase activity blocks memory at one phase while rescuing memory at other phases

Given the requirements for sustained kinase activity of the MAPK, the PKA, and the PKC pathways for the maintenance of ITM (Michel et al., 2012), it is possible that the differences in the phase of the circadian rhythms between ITM and LTM are the result of circadian regulation of kinase signaling. One mechanism through which the effectiveness of kinase signaling could be limited is regulated protein phosphatase activity. Aplysia neuronal protein phosphatases have been characterized with three protein phosphatases, PP1, PP2A, and calcineurin, accounting for $99 \%$ of neuronal phosphatase activity (Endo et al., 1992). In Aplysia, postsynaptic mechanisms of habituation require phosphatase activity for PP1 and/or PP2A (Ezzeddine and Glanzman, 2003; Esdin et al., 2010), whereas inhibition of calcineurin facilitates subthreshold training paradigms for sensitization (Sharma et al., 2003). As no previous studies have examined the role of phosphatases in LFI memory, we first tested the effects of phosphatase inhibition on animals trained at CT 3 using the phosphatase inhibitor okadaic acid. In mammals, PP2A appears more sensitive to inhibition by okadaic acid than PP1 (Hardie et al., 1991; Endo et al., 1992; Girault, 1993), but in Aplysia, okadaic acid potently blocks PP1 and PP2A (Endo et al., 1992). Similar to the requirement for protein phosphatase activity in habituation, we found that animals treated with okadaic acid 30 min before training exhibited no ITM, whereas vehicle-injected animals showed significant ITM (Fig. 4A; ANOVA: $F_{(3,43)}=16.52, p<0.0001$ ). The
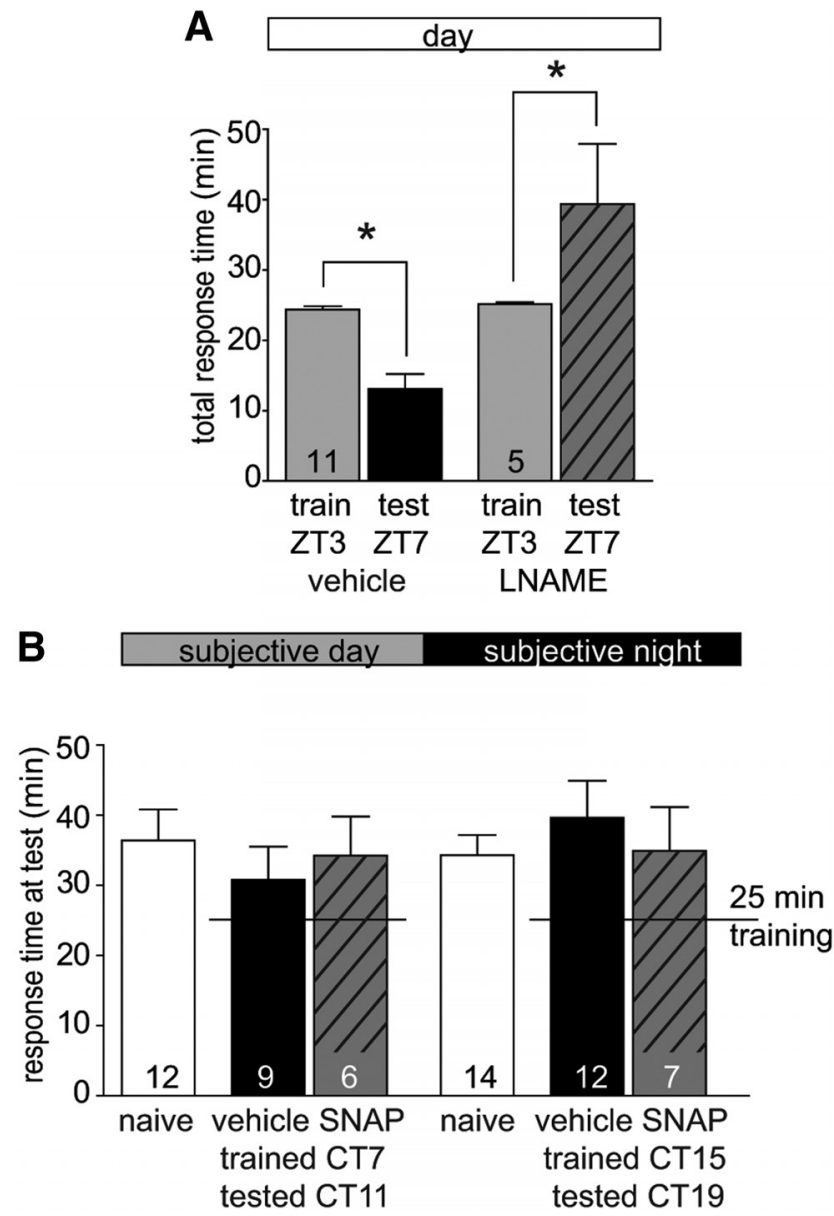

Figure 3. Exogenously supplied NO does not circumvent circadian suppression of ITM. $\boldsymbol{A}$ Massed training (25 min)-induced ITM is dependent upon NO as injection of the NO synthase inhibitor L-NAME ( $1 \mathrm{ml}$ of $10 \mathrm{mg} / \mathrm{ml}$ solution/100 g) before training completely blocked ITM in the treated animals, whereas vehicle-injected controls demonstrated robust ITM. B, Supplying exogenous N0 using SNAP ( $1 \mathrm{ml}$ of $10 \mathrm{mg} / \mathrm{ml}$ solution/100 g) before training at CT 7 (testing at CT 11) or CT 15 (testing at CT 19) on the second day of DD did not rescue ITM with observed testing times greater than training times in treated animals and similar to response times observed in vehicle-injected and naive animals. As predicted at these time points, vehicleinjected animals did not exhibit ITM. The horizontal dashed line indicates the training time of 25 min for visual comparison with the mean total response time during testing for each group. The $n$ values for all groups are shown in the figure. ${ }^{*} p<0.05$ (post hoc analyses using Bonferroni's multiple-comparison test).

drug alone did not induce lengthened feeding responses, as naive animals injected with the drug showed similar responses during testing compared with handled naive control animals (Fig. 4A). Potentially, treatment with okadaic acid delayed the induction and subsequent expression of ITM. To test this possibility, we injected animals with either okadaic acid or vehicle $30 \mathrm{~min}$ before training at CT 3 and tested the animals $6 \mathrm{~h}$ later for ITM. We found that vehicle-injected animals demonstrated robust ITM with significantly decreased testing times, whereas animals injected with okadaic acid did not exhibit ITM (vehicle-injected animals, $n=5$ : mean training time $=25.11 \pm 0.17 \mathrm{~min}$, mean testing time $=9.58 \pm 0.97 \mathrm{~min}$; okadaic acid-treated animals, $n=4$, mean training time $=25.82 \pm 0.24 \mathrm{~min}$, mean testing time $=36.11 \pm 4.30 \mathrm{~min}$; ANOVA: $\left.F_{(3,14)}=31.62, p<0.0001\right)$.

We performed additional experiments with a second phosphatase inhibitor to control for possible off-target effects of okadaic acid. We used calyculin A, a compound shown to effectively inhibit PP1 and PP2A in vivo and in vitro (Chatfield and Eastman, 

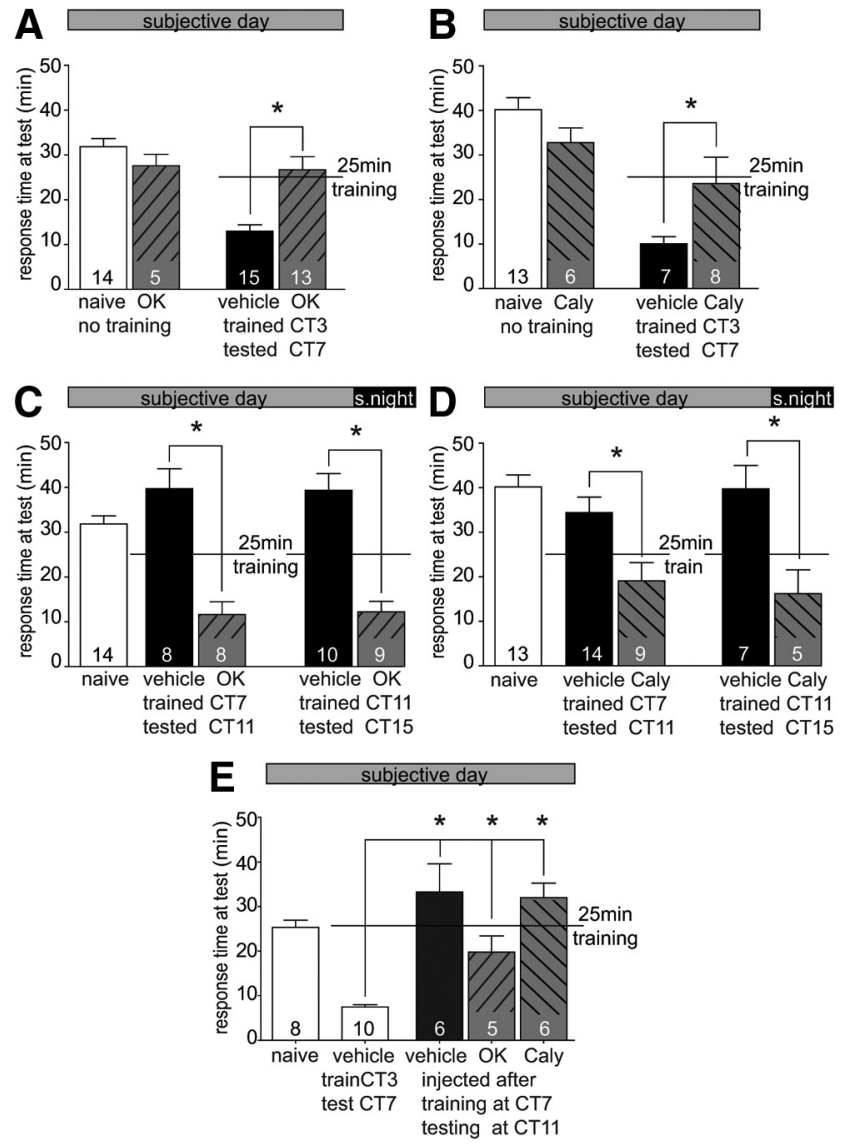

Figure 4. Inhibition of PP1 and PP2A inhibits ITM during the early day but rescues late day induction of ITM. All animals were trained on the second day of DD using a 25 min massed training protocol with training time denoted by the horizontal line. The mean total response time during testing is shown for each group. $A$, Animals were injected with either vehicle or the phosphatase inhibitor okadaic acid (OK; $1 \mathrm{ml} / 100 \mathrm{~g} 6.5 \mu \mathrm{m}$ stock solution, $\sim 100 \mathrm{~nm}$ final systemic concentration) $30 \mathrm{~min}$ before training and tested $4 \mathrm{~h}$ after training. Okadaic acid blocked the formation of ITM at CT 3 with response times significantly greater than vehicleinjected animals and similar to handled naive animals (white bars) or drug-injected animals receiving no training, whereas vehicle-injected animals demonstrated ITM exhibiting significantly decreased response times. $\boldsymbol{B}$, Injection of calyculin A (Caly; injection of $1 \mathrm{ml} / 100 \mathrm{~g} 0.65$ $\mu \mathrm{m}$ solution for $\sim 10 \mathrm{~nm}$ in the animal) before training blocked ITM when animals were trained at $\mathrm{CT} 3$ and tested $4 \mathrm{~h}$ after training. C, To test whether protein phosphatase inhibition rescued the induction of ITM at a time when ITM was usually inhibited, animals were injected with okadaic acid before training during the late subjective day. Injection of okadaic acid before training at CT 7 or CT 11 rescued induction of ITM with significantly decreased response times observed in treated animals upon testing $4 \mathrm{~h}$ later, whereas vehicle-injected animals demonstrated significantly longer response times. $\boldsymbol{D}$, Injection of calyculin A before training during the late subjective day at CT 7 or CT 11 rescued induction of ITM with significantly decreased response times observed in treated animals upon testing. Vehicle-injected animals exhibited significantly longer response times during testing. $\boldsymbol{E}$, Injection of protein phosphatase inhibitors immediately after training failed to rescue ITM. After training at $\mathrm{CT} 7$, animals were injected with vehicle, okadaic acid, or calyculin $\mathrm{A}$ and tested $4 \mathrm{~h}$ after training. Vehicle-injected animals and animals treated with the protein phosphatase inhibitors failed to show significant ITM, with testing responses not significantly different from the responses of naive animals. Control animals trained at CT 3 and tested $4 \mathrm{~h}$ later exhibited robust ITM with testing responses significantly different from each of the other groups. The $n$ values for all groups are shown in the figure. ${ }^{*} p<0.05$ (post hoc analyses using Bonferroni's multiple-comparison test).

2004; Kimura et al., 2008). Similarly to what was observed with okadaic acid, animals injected with calyculin A before training at CT 3 demonstrated no intermediate-term LFI memory when animals were tested $4 \mathrm{~h}$ after training. Drug only animals exhibited similar responses to naive animals (Fig. $4 B$; ANOVA: $F_{(3,30)}=$ $12.68, p<0.0001)$.
Although the above results suggest that protein phosphatase activity is necessary for massed training-induced ITM, it is possible that the level of protein phosphatase activity is a critical factor in memory formation with levels outside of a prescribed range, either too high or too low, unfavorable for memory. To test our hypothesis that high levels of phosphatase activity may be a limiting factor in memory formation at certain times of day, we treated animals with okadaic acid $30 \mathrm{~min}$ before training at either CT 7 or CT 11 and then tested the animals $4 \mathrm{~h}$ later. We found that okadaic acid-treated animals displayed significantly decreased response times compared with vehicle-treated or naive animals, indicating a rescue of ITM (Fig. $4 C$; ANOVA: $F_{(4,44)}=20.22, p<$ $0.0001)$. These results demonstrate that protein phosphatase inhibition phase specifically rescues ITM. To confirm these results, we repeated these experiments using calyculin A. We found that calyculin A also effectively rescued ITM for animals treated and trained during the late subjective day (Fig. $4 D$; ANOVA: $F_{(4,43)}=$ $7.11, p<0.001)$. These results suggest that the striking phase differences between circadian modulation of intermediateand long-term LFI memory may center on the differences in the requirements for persistent kinase activity during the formation of ITM.

The above results combined with the narrow temporal window for effective ITM training suggest that the circadian clock regulates the induction and early stages of memory formation. However, as sustained kinase activity is necessary for the maintenance of ITM, it is possible that circadian regulation of ITM targets later stages of memory formation or maintenance of memory. To test this possibility, animals were trained at CT 7 on the second day of DD and then injected with okadaic acid, calyculin A, or vehicle immediately after training. Animals were tested $4 \mathrm{~h}$ later at CT 11 . Control animals trained at CT 3 and tested at CT 7 displayed robust ITM with significantly decreased testing times compared with training (Fig. $4 E$ ). In contrast, for animals trained at CT 7 and injected with either vehicle or a protein phosphatase inhibitor after training, no ITM was observed. Vehicle-injected animals and animals injected with okadaic acid or calyculin A after training at CT 7 showed significantly greater response times than animals trained at CT 3 (Fig. 4E; ANOVA: $\left.F_{(4,30)}=13.79, p<0.0001\right)$. ANOVA revealed no significant differences between the training and testing times for any of the groups trained at CT 7 and injected after training with vehicle, okadaic acid, or calyculin A $\left(\right.$ ANOVA: $F_{(5,28)}=2.36, p>$ $0.05)$. No significant differences were observed between the testing response times of the three groups injected after training. Thus, the rescue of ITM only occurs when protein phosphatase inhibitors are administered before training. Overall, these studies suggest that circadian regulation of ITM occurs during the induction and early stages of memory formation rather than during the maintenance of memory.

\section{Inhibition of PP1 and PP2A rescues ITM during the early subjective night}

Circadian modulation of LFI training suppresses the formation of both ITM and LTM when training is performed at night. Although little is known about the factors modulating long-term LFI memory, mechanistic differences between ITM and LTM suggest that different mechanisms may modulate each form of memory. To determine whether ITM at night was also facilitated by inhibition of phosphatase activity, animals were treated with okadaic acid and trained either at CT 15 during the early night or CT 19 during the late night. During the first half of the night, treated animals trained at CT 15 showed significantly reduced 


\section{A}

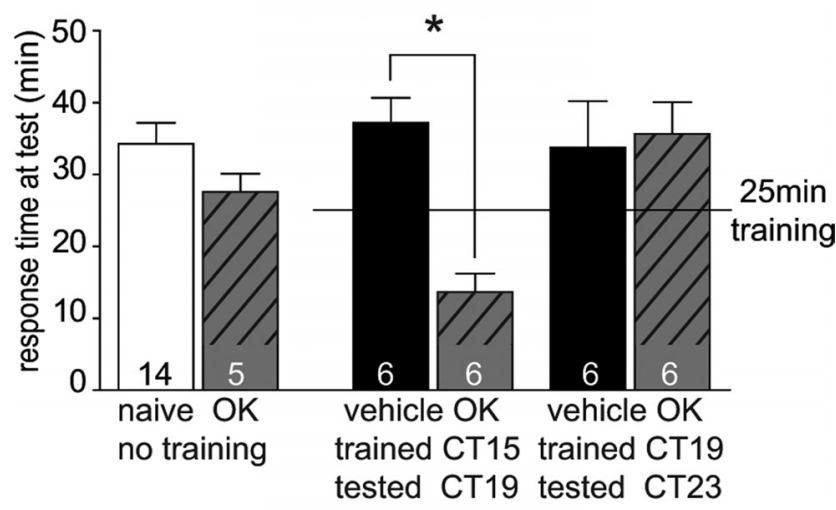

B subjective night

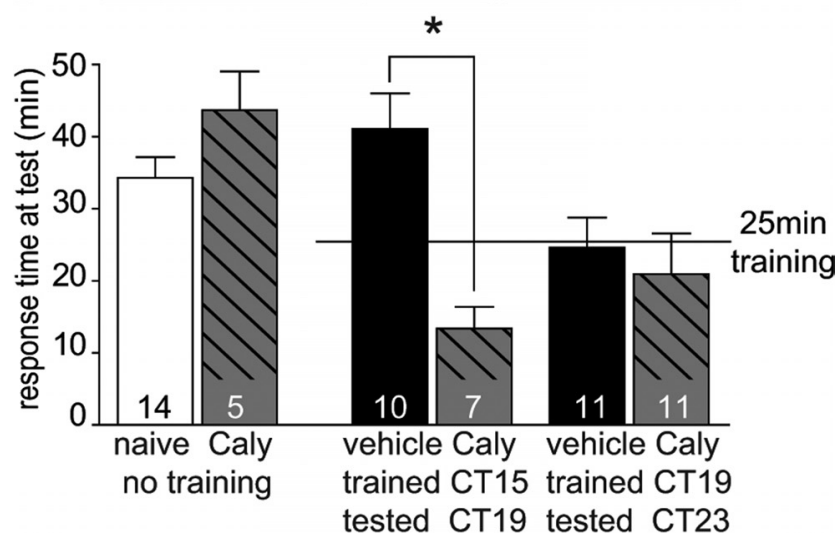

Figure 5. PP1 and PP2A inhibition rescues ITM formation during the early night, but not late night. All animals were trained on the second day of DD using a 25 min training protocol with training time denoted by the horizontal line. The mean total response time during testing for each group is shown. $\boldsymbol{A}$, To determine whether treatment of animals with the phosphatase inhibitors before training rescued ITM when training occurred at night, animals were injected with okadaic acid before training at either $\mathrm{CT} 15$ or CT 19. Animals treated before training at CT 15 demonstrated robust ITM upon testing with significantly decreased response times compared with vehicle-injected or naive animals. However, when animals were treated and trained at CT 19, no ITM was observed with comparable response times to vehicle-injected or naive animals. B, Similarly, animals were injected with calyculin A before training at either CT 15 or CT 19. Animals treated before training at $C T 15$ demonstrated robust ITM upon testing with significantly decreased response times compared with vehicle-injected or naive animals. At CT 19, there was no significant difference in testing times between the calyculin A-treated animals and vehicle-injected or naive animals. Thus, okadaic acid and calyculin A phase specifically rescued ITM during the subjective day and during the early night, but not the late night. The $n$ values for all groups are shown in the figure. ${ }^{*} p<0.05$ (post hoc analyses using Bonferroni's multiplecomparison test).

responses upon testing indicating ITM, whereas vehicle-injected animals demonstrated no ITM (Fig. 5A; ANOVA: $F_{(5,37)}=4.41$, $p<0.01)$. However, when okadaic acid-injected animals were trained during the late night at CT 19, no rescue of memory was observed. Experimental and vehicle-injected animals showed similar response times to naive or drug only treated animals (Fig. $5 A$ ). Thus, it appears that okadaic acid phase specifically rescues memory when training occurs during the early, but not late night. We confirmed the above results through similar experiments using calyculin A and found that calyculin A treatment also resulted in significantly decreased response times compared with vehicleinjected animals when animals were trained at CT 15 (Fig. 5B; ANOVA: $\left.F_{(5,52)}=5.71, p<0.001\right)$. Calyculin A alone did not cause a significant shortening of response times at night as ani- mals that received calyculin A, but no training, showed similar response times to naive animals. With training at CT 19, calyculin A-treated animals responded similarly to vehicle-injected animals, indicating a lack of ITM formation in these animals (Fig. $5 B)$. Thus, it appears that calyculin A treatment before training at CT 19 was not sufficient to overcome circadian inhibition of memory.

\section{Calcineurin inhibition rescues memory during the late-subjective night}

The above experiments clearly demonstrate that inhibition of PP1 and PP2A phosphatase activity rescues memory during the late subjective day and in the early subjective night. However, memory formation still appeared suppressed when training occurred during the late subjective night. In Aplysia, the protein phosphatase calcineurin has been shown to be a factor limiting the formation of sensitization for subthreshold training paradigms (Sharma et al., 2003). Furthermore, inhibition of calcineurin facilitates MAPK signaling (Sharma et al., 2003). As intermediate-term LFI memory requires MAPK for both its induction and maintenance, it is possible that calcineurin acts as a repressive factor in the circadian regulation of ITM.

We first investigated whether inhibition of calcineurin at CT 3 affected ITM. Animals were injected with the inhibitor FK 506, 30 min before training and then tested $4 \mathrm{~h}$ later. In contrast to the block of ITM observed when PP1 and PP2A were inhibited, animals treated with FK 506 before training exhibited significantly decreased response times with robust ITM similar to vehicleinjected animals (Fig. 6A). We then tested whether treatment with FK 506 could rescue the circadian suppression of ITM memory during the subjective day. Animals were treated with FK 506 and then trained at either CT 7 or CT 11. We found that FK 506 facilitated training during the subjective day, with treated animals demonstrating significantly decreased response times compared with vehicle-injected or naive animals (Fig. 6A; ANOVA: $\left.F_{(7,54)}=14.92, p<0.0001\right)$. As with the inhibition of PP1 and PP2A, inhibition of calcineurin appears sufficient to overcome circadian suppression of ITM during the late subjective day.

To determine whether calcineurin also affects ITM during the subjective night, animals were treated with FK 50630 min before training at either CT 15 or CT 19. Similar to the results observed with calyculin A and okadaic acid, FK 506-treated animals trained at CT 15 demonstrated robust ITM with significantly decreased response times compared with vehicle-injected or naive animals. However, in contrast to calyculin A or okadaic acid treatment, FK506 treatment rescued intermediate-term LFI memory when animals were trained during the late subjective night at CT 19 (Fig. 6B; ANOVA: $F_{(5,34)}=5.90, p<0.001$ ). These results suggest that the circadian inhibition of memory observed during the late night is primarily through a pathway mediated by the phosphatase activity of calcineurin.

\section{Discussion}

Over the past decade, the impact of the circadian clock on memory has become evident from research in insects, marine invertebrates, fish, and mammals (for review, see Gerstner et al., 2009; Gerstner and Yin, 2010). However, little is known regarding the mechanisms underlying circadian modulation of memory, an essential requirement for improving memory function in today's global society. Aplysia has proven highly instructive for detailing circadian modulation of memory formation for associative and nonassociative learning (Fernandez et al., 2003; Lyons et al., 2005). We investigated circadian regulation of ITM using an op- 

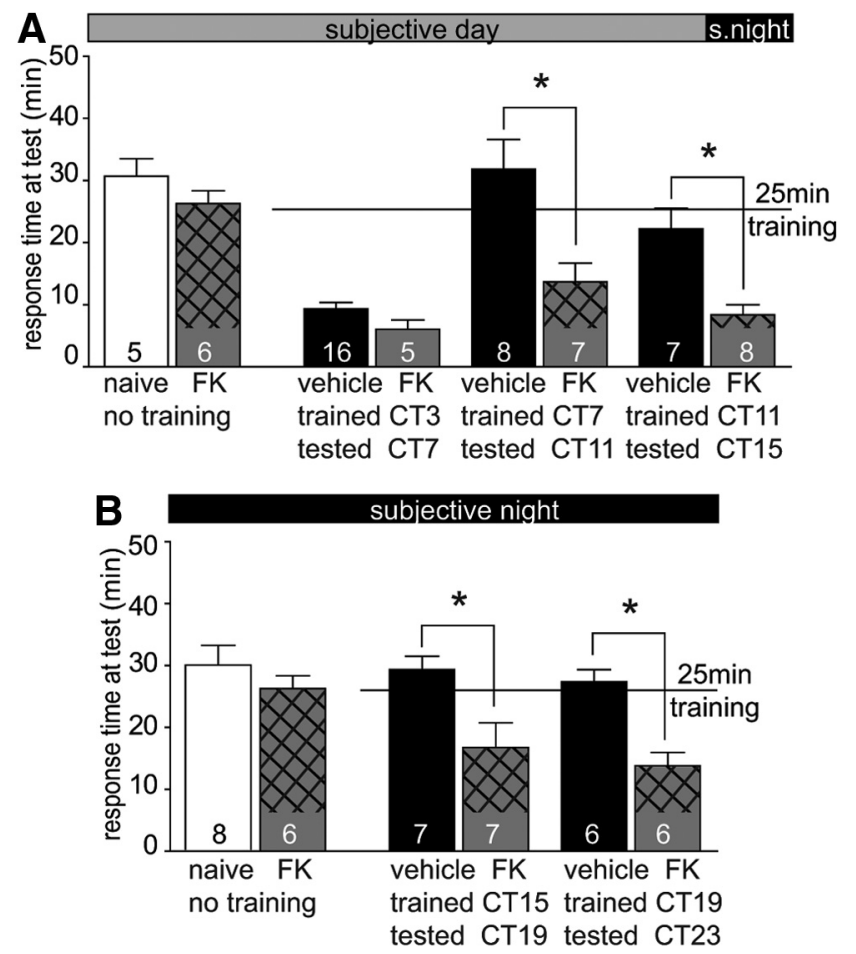

Figure 6. Calcineurin inhibition does not inhibit ITM during the early day and facilitates ITM formation throughout the late day and night. All animals were trained on the second day of DD using a 25 min training protocol with training time denoted by the horizontal line. The mean total response time during testing is shown for each group. $A$, Unlike $0 \mathrm{~K}$ and calyculin $\mathrm{A}$, inhibition of calcineurin with FK506 (130 $\mu \mathrm{m} / 100 \mathrm{~g}$ of $5 \mathrm{~mm}$ stock DMSO solution) before training at CT 3 did not block the induction of ITM. Treated animals displayed ITM with decreased response times comparable with vehicle-injected animals. Treatment of animals with FK506 before training during the late subjective day at CT 7 or CT 11 also resulted in significant ITM as opposed to vehicle-injected animals. FK506 treatment in the absence of training did not alter responses. $\boldsymbol{B}$, In contrast to PP1 and PP2A inhibition, inhibition of calcineurin before training permitted robust ITM during both the early (CT 15) and the late night (CT 19) with observed response times significantly decreased compared with vehicle-injected and naive animals. The $n$ values for all groups are shown in the figure. ${ }^{*} p<0.05$ (post hoc analyses using Bonferroni's multiplecomparison test).

erant paradigm, taking advantage of the highly plastic neurocircuitry associated with feeding behaviors in Aplysia. We found that the circadian clock strongly regulated ITM formation with a narrow window supporting induction of memory. Efficacious training occurred only when animals were trained early in the (subjective) day. Surprisingly, the same restrictive circadian regulation of ITM was observed using a spaced training paradigm, although spaced training is generally considered a stronger induction protocol than massed training (Carew et al., 1972; Mandel et al., 1989; Tully et al., 1994; Kogan et al., 1997; Beck et al., 2000; Amano and Maruyama, 2011; Kramár et al., 2012). Our results suggest that massed training for LFI effectively induces ITM similarly to spaced training.

Functionally, it is difficult to decipher the need for such a restricted window for ITM. As LFI involves an ethologically relevant complex behavior, potentially circadian regulation of other behaviors, such as the drive to feed masks ITM. Although the limited window of ITM expression prevented us from directly testing whether circadian regulation of recall occurs, we find this possibility unlikely as we found that protein phosphatase inhibition before, but not after, training during the late subjective day rescued ITM, suggesting circadian regulation of the induction and formation of ITM. Additionally, the same training protocol induces LTM and STM when animals are trained during the late subjective day (Lyons et al., 2005), making it unlikely that a circadian rhythm in feeding or another behavior selectively occludes ITM.

Potentially, the adaptive advantages for circadian regulation of ITM are related to predicted behaviors at times when memory would be recalled. Aplysia exhibit diurnal rhythms in feeding behavior (Kupfermann, 1974; Levenson et al., 1999). If animals receive training during the late day or night, then ITM expressed 4-6 h after training spans a time period in which recall of the memory is unlikely based upon behavior patterns of the animal. The lack of ITM at certain phases may represent a potential advantage over continuous ITM formation. Research in insects suggests that a balance exists between the advantages of memory and negative consequences resulting from metabolic and fitness costs induced by continuous learning or memory formation requiring macromolecular synthesis (Mery and Kawecki, 2004, 2005; Burns et al., 2011; Plaçais and Preat, 2013). Although LTM also requires macromolecular synthesis, the costs of a broader window for LTM induction may be counterbalanced as LTM expression affects behavior across circadian phases for days (Lyons et al., 2005). We therefore suggest that time of training is critical in determining induction and formation of ITM with predicted behavioral outcomes providing an adaptive advantage of circadian modulation.

Although ITM and LTM share similar requirements for memory induction, including MAPK, PKA, and PKC activity, the maintenance requirements differ considerably with ITM dependent on prolonged kinase activity (Michel et al., 2011a; 2011b, 2012). We investigated protein phosphatase activity as a potential regulator of ITM. We found that inhibition of PP1 and PP2A activity through okadaic acid or calyculin A blocked ITM when animals were trained at CT 3, whereas no such blockade was observed with inhibition of calcineurin. Previous research found that okadaic acid and calyculin A blocked expression of passive avoidance memory in chicks during a temporally similar time frame (Zhao et al., 1995; Bennett et al., 2001). Potentially, inhibition of protein phosphatase activity at CT 3 limits protein synthesis, a requirement for ITM (Michel et al., 2012). In mammals, PP1 and PP2A dephosphorylate eiF2 $\alpha$, which when hypophosphorylated leads to initiation of translation (Redpath and Proud, 1990; Wakula et al., 2006). eiF2 $\alpha$ phosphorylation also regulates translation-dependent late-long-term potentiation in mice with dephosphorylation leading to potentiation and increased phosphorylation leading to memory impairment (Costa-Mattioli et al., 2007). Similarly, PP2A dephosphorylates eukaryotic elongation factor 2 (eEF2; (Redpath and Proud, 1990). Phosphorylation of eEF2 inhibits translation (Ryazanov et al., 1988), and fear conditioning in mammals rapidly induces eEF2 dephosphorylation in the hippocampus and the amygdala (Im et al., 2009). In Aplysia, induction of long-term facilitation also decreases eEF2 phosphorylation (Carroll et al., 2004; Weatherill et al., 2011), providing evidence for the importance of phosphatase activity in translation and memory formation.

Given the requirement for prolonged signaling through multiple kinases during maintenance of ITM, we hypothesized that high levels of phosphatase activity during the late day and night may inhibit persistent kinase activity. Previous research demonstrated that circadian regulation of outputs in chicks could occur through circadian regulation of calcineurin activity (Huang et al., 2012). Using a pharmacological approach, we found that the circadian clock appears to modulate ITM through differential protein phosphatase activity as inhibition rescues memory when 
training occurs during the late day and night. Because of technical limitations, measurements of phosphatase activity in Aplysia ganglia are not sensitive enough to determine whether individual phosphatases exhibit circadian activity (data not shown). We found that treatment with okadaic acid or calyculin A before training, but not after training, rescued memory when animals were trained during the late subjective day (CT 7 and CT 11) or early subjective night (CT 15). Similarly, inhibition of calcineurin at these times also rescued ITM. During the late night, inhibition of calcineurin, but not of PP1 or PP2A, rescued ITM, suggesting that higher calcineurin activity may occur during the late night compared with late day or early night. Combined, these results indicate that phosphatase activity is a critical factor for ITM throughout all circadian phases, but the protein phosphatases most active may differ with time of day.

What are the most likely targets of protein phosphatases during the inhibition of ITM? Persistent kinase activity and protein translation are pivotal for ITM (Michel et al., 2012). PKC signaling is necessary for ITM maintenance, but not LTM, making this pathway a likely target for differential regulation (Michel et al., 2011a; 2012). Recently, calyculin A treatment was shown to prevent 5-HT-induced translocation of PKC Apl II to the plasma membrane (Farah et al., 2012). Dephosphorylation appears necessary for PKC membrane translocation as autophosphorylation may limit translocation for both PKC Apl I and Apl II (Nakhost et al., 1999; Farah et al., 2012). Whereas the compartmentalization of PKC isoforms remains unknown for LFI, massed traininginduced facilitation results in persistent PKC translocation to the membrane (Farah et al., 2009; Jin et al., 2011), suggesting a role for protein phosphatase activity and a possible mechanism that may also be required in LFI memory.

Protein phosphatase activity may affect the efficacy of persistent PKA activation via dephosphorylation of kinase targets. PP1 and calcineurin dephosphorylate proteins phosphorylated by PKA during long-term potentiation (for review, see Abel and Nguyen, 2008). Dephosphorylation of synaptic PKA targets could aid in suppressing ITM during the late day and night. However, during the late subjective day, formation of long-term LFI memory is robust. Unlike ITM, the role for PKA in LTM presumably centers on its nuclear translocation and phosphorylation of transcription factors.

Persistent MAPK is required for both ITM and LTM. Unlike LTM, ITM requires sustained MAPK activity throughout maintenance (Michel et al., 2011b; 2012). Calcineurin activity negatively regulates MAPK signaling in Aplysia as inhibition of calcineurin facilitates MAPK activation and the induction of intermediate-term sensitization (Sharma et al., 2003). The MAPK pathway may be a target of PP2A as mammalian cell culture studies demonstrated that PP2A coimmunoprecipitates with MAPK (Wang et al., 2006) and dephosphorylates ERK2 (Zhou et al., 2002). If phosphatase activity is higher during the night, this may limit the sustained activation of MAPK required for ITM and represents a plausible mechanism through which protein phosphatase inhibition rescues ITM during the late day and night.

Increasing societal globalization has rapidly escalated the demands upon individuals for continual high performance outside of traditional working hours. Yet, the means to alleviate circadian restrictions on memory and performance have not been identified. Our results demonstrate that the circadian clock specifically regulates different temporal forms of memory and highlight the value of Aplysia as a model for delineating the complexities of circadian modulation of memory. Furthermore, our studies broadly outlined protein phosphatase activity as a mechanism through which the circadian clock phase specifically regulates ITM, suggesting potential targets for improving memory. Future studies will aid our understanding of the cellular location and targets of protein phosphatases during the circadian regulation of memory. These studies further emphasize the continuing value provided by studies of memory formation using an in vivo invertebrate model system with a relatively simple nervous system (Abrams, 2012).

\section{References}

Abel T, Nguyen PV (2008) Regulation of hippocampus-dependent memory by cyclic AMP-dependent protein kinase. Prog Brain Res 169:97-115. CrossRef Medline

Abrams TW (2012) Studies on Aplysia neurons suggest treatments for chronic human disorders. Curr Biol 22:R705-R711. CrossRef Medline

Alberini CM, Ghirardi M, Metz R, Kandel ER (1994) C/EBP is an immediate-early gene required for the consolidation of long-term facilitation in Aplysia. Cell 76:1099-1114. CrossRef Medline

Amano H, Maruyama IN (2011) Aversive olfactory learning and associative long-term memory in Caenorhabditis elegans. Learn Mem 18:654-665. CrossRef Medline

Barbosa FF, Albuquerque FS (2008) Effect of the time-of-day of training on explicit memory. Braz J Med Biol Res 41:477-481. CrossRef Medline

Beck CD, Schroeder B, Davis RL (2000) Learning performance of normal and mutant Drosophila after repeated conditioning trials with discrete stimuli. J Neurosci 20:2944-2953. Medline

Bennett PC, Zhao W, Ng KT (2001) Concentration-dependent effects of protein phosphatase (PP) inhibitors implicate PP1 and PP2A in different stages of memory formation. Neurobiol Learn Mem 75:91-110. CrossRef Medline

Botzer D, Markovich S, Susswein AJ (1998) Multiple memory processes following training that a food is inedible in Aplysia. Learn Mem 5:204-219. CrossRef Medline

Burns JG, Foucaud J, Mery F (2011) Costs of memory: lessons from "mini" brains. Proc Biol Sci 278:923-929. CrossRef Medline

Carew TJ, Pinsker HM, Kandel ER (1972) Long-term habituation of a defensive withdrawal reflex in aplysia. Science 175:451-454. CrossRef Medline

Carroll M, Warren O, Fan X, Sossin WS (2004) 5-HT stimulates eEF2 dephosphorylation in a rapamycin-sensitive manner in Aplysia neurites. J Neurochem 90:1464-1476. CrossRef Medline

Chatfield K, Eastman A (2004) Inhibitors of protein phosphatases 1 and 2A differentially prevent intrinsic and extrinsic apoptosis pathways. Biochem Biophys Res Commun 323:1313-1320. CrossRef Medline

Chaudhury D, Colwell CS (2002) Circadian modulation of learning and memory in fear-conditioned mice. Behav Brain Res 133:95-108. CrossRef Medline

Costa-Mattioli M, Gobert D, Stern E, Gamache K, Colina R, Cuello C, Sossin W, Kaufman R, Pelletier J, Rosenblum K, Krnjević K, Lacaille JC, Nader K, Sonenberg N (2007) eIF2 $\alpha$ phosphorylation bidirectionally regulates the switch from short- to long-term synaptic plasticity and memory. Cell 129:195-206. CrossRef Medline

Decker S, McConnaughey S, Page TL (2007) Circadian regulation of insect olfactory learning. Proc Natl Acad Sci U S A 104:15905-15910. CrossRef Medline

Endo S, Shenolikar S, Eskin A, Zwartjes RE, Byrne JH (1992) Characterization of neuronal protein phosphatases in Aplysia californica. J Neurochem 58:975-982. CrossRef Medline

Esdin J, Pearce K, Glanzman DL (2010) Long-term habituation of the gillwithdrawal reflex in aplysia requires gene transcription, calcineurin and L-type voltage-gated calcium channels. Front Behav Neurosci 4:181. CrossRef Medline

Ezzeddine Y, Glanzman DL (2003) Prolonged habituation of the gillwithdrawal reflex in Aplysia depends on protein synthesis, protein phosphatase activity, and postsynaptic glutamate receptors. J Neurosci 23 : 9585-9594. Medline

Farah CA, Weatherill D, Dunn TW, Sossin WS (2009) PKC differentially translocates during spaced and massed training in Aplysia. J Neurosci 29:10281-10286. CrossRef Medline

Farah CA, Lindeman AA, Siu V, Gupta MD, Sossin WS (2012) Autophos- 
phorylation of the $\mathrm{C} 2$ domain inhibits translocation of the novel protein kinase c (nPKC) Apl II. J Neurochem 123:360-372. CrossRef Medline

Fernandez RI, Lyons LC, Levenson J, Khabour O, Eskin A (2003) Circadian modulation of long-term sensitization in Aplysia. Proc Natl Acad Sci U S A 100:14415-14420. CrossRef Medline

Folkard S, Monk TH (1980) Circadian rhythms in human memory. Br J Psychol 71:295-307. CrossRef

Gerstner JR, Yin JC (2010) Circadian rhythms and memory formation. Nat Rev Neurosci 11:577-588. CrossRef Medline

Gerstner JR, Lyons LC, Wright KP Jr, Loh DH, Rawashdeh O, Eckel-Mahan KL, Roman GW (2009) Cycling behavior and memory formation. J Neurosci 29:12824-12830. CrossRef Medline

Girault JA (1993) Protein phosphorylation and dephosphorylation in mammalian central nervous system. Neurochem Int 23:1-25. CrossRef Medline

Gritton HJ, Kantorowski A, Sarter M, Lee TM (2012) Bidirectional interactions between circadian entrainment and cognitive performance. Learn Mem 19:126-141. CrossRef Medline

Hardie DG, Haystead TA, Sim AT (1991) Use of okadaic acid to inhibit protein phosphatases in intact cells. Methods Enzymol 201:469-476. CrossRef Medline

Hattar S, Lyons LC, Dryer L, Eskin A (2002) Circadian regulation of a transcription factor, ApC/EBP, in the eye of Aplysia californica. J Neurochem 83:1401-1411. CrossRef Medline

Huang CC, Ko ML, Vernikovskaya DI, Ko GY (2012) Calcineurin serves in the circadian output pathway to regulate the daily rhythm of L-type voltage-gated calcium channels in the retina. J Cell Biochem 113:911-922. CrossRef Medline

Im HI, Nakajima A, Gong B, Xiong X, Mamiya T, Gershon ES, Zhuo M, Tang YP (2009) Post-training dephosphorylation of eEF-2 promotes protein synthesis for memory consolidation. PLoS One 4:e7424. CrossRef Medline

Jin I, Kandel ER, Hawkins RD (2011) Whereas short-term facilitation is presynaptic, intermediate-term facilitation involves both presynaptic and postsynaptic protein kinases and protein synthesis. Learn Mem 18:96-102. CrossRef Medline

Katzoff A, Ben-Gedalya T, Susswein AJ (2002) Nitric oxide is necessary for multiple memory processes after learning that a food is inedible in Aplysia. J Neurosci 22:9581-9594. Medline

Katzoff A, Ben-Gedalya T, Hurwitz I, Miller N, Susswein YZ, Susswein AJ (2006) Nitric oxide signals that aplysia have attempted to eat, a necessary component of memory formation after learning that food is inedible. J Neurophysiol 96:1247-1257. CrossRef Medline

Kimura S, Kawasaki S, Watanabe S, Fujita R, Sasaki K (2008) Regulatory roles of $\mathrm{Ca}^{2+} /$ calmodulin-dependent protein kinase II and protein phosphatase $2 \mathrm{~A}$ on the quisqualic acid-induced $\mathrm{K}^{+}$-current response in identified neurons of Aplysia. Neurosci Res 60:73-81. CrossRef Medline

Kogan JH, Frankland PW, Blendy JA, Coblentz J, Marowitz Z, Schütz G, Silva AJ (1997) Spaced training induces normal long-term memory in CREB mutant mice. Curr Biol 7:1-11. CrossRef Medline

Kramár EA, Babayan AH, Gavin CF, Cox CD, Jafari M, Gall CM, Rumbaugh G, Lynch G (2012) Synaptic evidence for the efficacy of spaced learning. Proc Natl Acad Sci U S A 109:5121-5126. CrossRef Medline

Krishnan B, Dryer SE, Hardin PE (1999) Circadian rhythms in olfactory responses of Drosophila melanogaster. Nature 400:375-378. CrossRef Medline

Kupfermann I (1974) Feeding behavior in Aplysia: a simple system for the study of motivation. Behav Biol 10:1-26. CrossRef Medline

Levenson J, Byrne JH, Eskin A (1999) Levels of serotonin in the hemolymph of Aplysia are modulated by light/dark cycles and sensitization training. J Neurosci 19:8094-8103. Medline

Levitan D, Lyons LC, Perelman A, Green CL, Motro B, Eskin A, Susswein AJ (2008) Training with inedible food in Aplysia causes expression of C/EBP in the buccal but not cerebral ganglion. Learn Mem 15:412-416. CrossRef Medline

Lickey ME, Block GD, Hudson DJ, Smith JT (1976) Circadian oscillators and photoreceptors in the gastropod, Aplysia. Photophysiology 23:253-273. Medline

Lyons LC, Roman G (2009) Circadian modulation of short-term memory in Drosophila. Learn Mem 16:19-27. CrossRef Medline

Lyons LC, Rawashdeh O, Katzoff A, Susswein AJ, Eskin A (2005) Circadian modulation of complex learning in diurnal and nocturnal Aplysia. Proc Natl Acad Sci U S A 102:12589-12594. CrossRef Medline

Lyons LC, Green CL, Eskin A (2008) Intermediate-term memory is modulated by the circadian clock. J Biol Rhythms 23:538-542. CrossRef Medline

Mandel RJ, Gage FH, Thal LJ (1989) Enhanced detection of nucleus basalis magnocellularis lesion-induced spatial learning deficit in rats by modification of training regimen. Behav Brain Res 31:221-229. CrossRef Medline

Menzel R, Manz G, Menzel R, Greggers U (2001) Massed and spaced learning in honeybees: the role of CS, US, the intertrial interval, and the test interval. Learn Mem 8:198-208. CrossRef Medline

Mery F, Kawecki TJ (2004) The effect of learning on experimental evolution of resource preference in Drosophila melanogaster. Evolution 58:757-767. CrossRef Medline

Mery F, Kawecki TJ (2005) A cost of long-term memory in Drosophila. Science 308:1148. CrossRef Medline

Michel M, Green CL, Lyons LC (2011a) PKA and PKC are required for long-term but not short-term in vivo operant memory in Aplysia. Learn Mem 18:19-23. CrossRef Medline

Michel M, Green CL, Eskin A, Lyons LC (2011b) PKG-mediated MAPK signaling is necessary for long-term operant memory in Aplysia. Learn Mem 18:108-117. CrossRef Medline

Michel M, Green CL, Gardner JS, Organ CL, Lyons LC (2012) Massed training-induced intermediate-term operant memory in Aplysia requires protein synthesis and multiple persistent kinase cascades. J Neurosci 32: 4581-4591. CrossRef Medline

Miller N, Saada R, Fishman S, Hurwitz I, Susswein AJ (2011) Neurons controlling Aplysia feeding inhibit themselves by continuous NO production. PLoS One 6:e17779. CrossRef Medline

Nakhost A, Dyer JR, Pepio AM, Fan X, Sossin WS (1999) Protein kinase C phosphorylated at a conserved threonine is retained in the cytoplasm. J Biol Chem 274:28944-28949. CrossRef Medline

Philips GT, Tzvetkova EI, Carew TJ (2007) Transient mitogen-activated protein kinase activation is confined to a narrow temporal window required for the induction of two-trial long-term memory in Aplysia. J Neurosci 27:13701-13705. CrossRef Medline

Plaçais PY, Preat T (2013) To favor survival under food shortage, the brain disables costly memory. Science 339:440-442. CrossRef Medline

Rawashdeh O, de Borsetti NH, Roman G, Cahill GM (2007) Melatonin suppresses nighttime memory formation in zebrafish. Science 318: 1144-1146. CrossRef Medline

Redpath NT, Proud CG (1990) Activity of protein phosphatases against initiation factor-2 and elongation factor-2. Biochem J 272:175-180. Medline

Ruby NF, Hwang CE, Wessells C, Fernandez F, Zhang P, Sapolsky R, Heller HC (2008) Hippocampal-dependent learning requires a functional circadian system. Proc Natl Acad Sci U S A 105:15593-15598. CrossRef Medline

Ryazanov AG, Shestakova EA, Natapov PG (1988) Phosphorylation of elongation factor 2 by EF- 2 kinase affects rate of translation. Nature 334:170-173. CrossRef Medline

Sharma SK, Bagnall MW, Sutton MA, Carew TJ (2003) Inhibition of calcineurin facilitates the induction of memory for sensitization in Aplysia: requirement of mitogen-activated protein kinase. Proc Natl Acad Sci U S A 100:4861-4866. CrossRef Medline

Susswein AJ, Schwarz M, Feldman E (1986) Learned changes of feeding behavior in Aplysia in response to edible and inedible foods. J Neurosci 6:1513-1527. Medline

Sutton MA, Ide J, Masters SE, Carew TJ (2002) Interaction between amount and pattern of training in the induction of intermediate- and long-term memory for sensitization in aplysia. Learn Mem 9:29-40. CrossRef Medline

Takahashi JS, Turek FW, Moore RY (2001) Circadian clocks. New York: Kluwer Academic/Plenum.

Tully T, Preat T, Boynton SC, Del Vecchio M (1994) Genetic dissection of consolidated memory in Drosophila. Cell 79:35-47. CrossRef Medline

Valentinuzzi VS, Menna-Barreto L, Xavier GF (2004) Effect of circadian phase on performance of rats in the Morris water maze task. J Biol Rhythms 19:312-324. CrossRef Medline

Valentinuzzi VS, Neto SP, Carneiro BT, Santana KS, Araújo JF, Ralph MR (2008) Memory for time of training modulates performance on a place 
conditioning task in marmosets. Neurobiol Learn Mem 89:604-607. CrossRef Medline

Wakula P, Beullens M, van Eynde A, Ceulemans H, Stalmans W, Bollen M (2006) The translation initiation factor eIF $2 \beta$ is an interactor of protein phosphatase-1. Biochem J 400:377-383. CrossRef Medline

Wang Z, Yang H, Tachado SD, Capó-Aponte JE, Bildin VN, Koziel H, Reinach PS (2006) Phosphatase-mediated crosstalk control of ERK and p38 MAPK signaling in corneal epithelial cells. Invest Ophthalmol Vis Sci 47:5267-5275. CrossRef Medline

Weatherill DB, McCamphill PK, Pethoukov E, Dunn TW, Fan X, Sossin WS (2011) Compartment-specific, differential regulation of eukaryotic elon- gation factor 2 and its kinase within Aplysia sensory neurons. J Neurochem 117:841-855. CrossRef Medline

Wright KP, Lowry CA, Lebourgeois MK (2012) Circadian and wakefulnesssleep modulation of cognition in humans. Front Mol Neurosci 5:50. CrossRef Medline

Zhao W, Bennett P, Sedman GL, Ng KT (1995) The impairment of longterm memory formation by the phosphatase inhibitor okadaic acid. Brain Res Bull 36:557-561. CrossRef Medline

Zhou B, Wang ZX, Zhao Y, Brautigan DL, Zhang ZY (2002) The specificity of extracellular signal-regulated kinase 2 dephosphorylation by protein phosphatases. J Biol Chem 277:31818-31825. CrossRef Medline 